\title{
Statistics and Characteristics Analysis of China's Intellectual Property Crimes
}

\author{
Yingyu $\mathrm{Bao}^{1, \mathrm{a}}$ \\ ${ }^{1}$ Associate professor of Law School of Yang-En University, Quanzhou, Fujian, China \\ a'Email: yybao@yeu.edu.cn
}

\begin{abstract}
By collecting, comparing and analyzing the data of intellectual property crime cases officially published, it is found that there is a big contrast between the quantity and the actual situation. Such crimes have the possibility of the existence of large-scale crime black numbers, the expansion of the scope of real-world crime objects, and the difficulty of eradicating criminal objects in virtual worlds. It should be given priority in the legal framework to reduce the phenomenon of intellectual property crime.
\end{abstract}

Keywords: Intellectual property crime; Data statistics; Criminal black number

\section{Introduction}

Intellectual property crimes, known as economic drugs, do not seem to have a large surface impact in the short term, but the real and long-term harm is staggering. Therefore, the infringement of Intellectual property crimes has become one of the most serious crimes committed by the United Nations in 17 types of transnational crimes. [1] Intellectual property crimes in China refer to the acts that occur in the field of intellectual property rights, infringe the relevant intellectual property rights system, and should be punished according to law. In a narrow sense, intellectual property crime refers to a section of the crime of undermining the socialist market economic order in the current Criminal Law, which contains seven specific crimes. In addition to the above crimes, the crimes of intellectual property in a broad sense include crimes that do not infringe the relevant specific intellectual property rights, but violate the relevant intellectual property rights system. At the same time, the judicial practice is based on the competition and competition of laws and regulations and the acception and rejection of evidence. The related crimes include but are not limited to the crime of producing and selling fake and inferior commodities, the crime of illegal operation, and the related computer crimes.

\section{Data statistics of intellectual property crime}

"The significance of data to us begins to transcend the virtual world itself and make a real connection with real life, so that many activities in the cyber space begin to present objective features."[2] The data itself is boring, and there may be a lot of deviation due to factors such as statistical methods, but after all, a window is opened.[3] According to the "Intellectual Property White Paper" of the State Intellectual Property Office and the "State of Intellectual Property Judicial Protection of Chinese Courts" issued by the Supreme People's Court[4], the author conducts preliminary statistics on criminal cases of intellectual property rights.

\subsection{An overview of the number of cases nationwide over the years}

As shown in Table 1, the number of intellectual property cases and the number of crimes in the broad sense of our country are increasing year by year, with the largest increase in 2012, and the number of cases increases by $132.4 \%$ over the same period. The main reason is the "Sword" campaign organized by the national public security organs from September 1, 2011 to December 31, 2011 to fight against intellectual property crimes. The delay is evident in the 2012 figures, as it need take some time for the review of prosecutions and judgments. Therefore, Table 1 shows that intellectual property crimes are rampant, and without special remedies, it is likely to maintain a high level of operation. 
Table 1: First instance cases of intellectual property crimes and number of offenders in court in 2005-2015

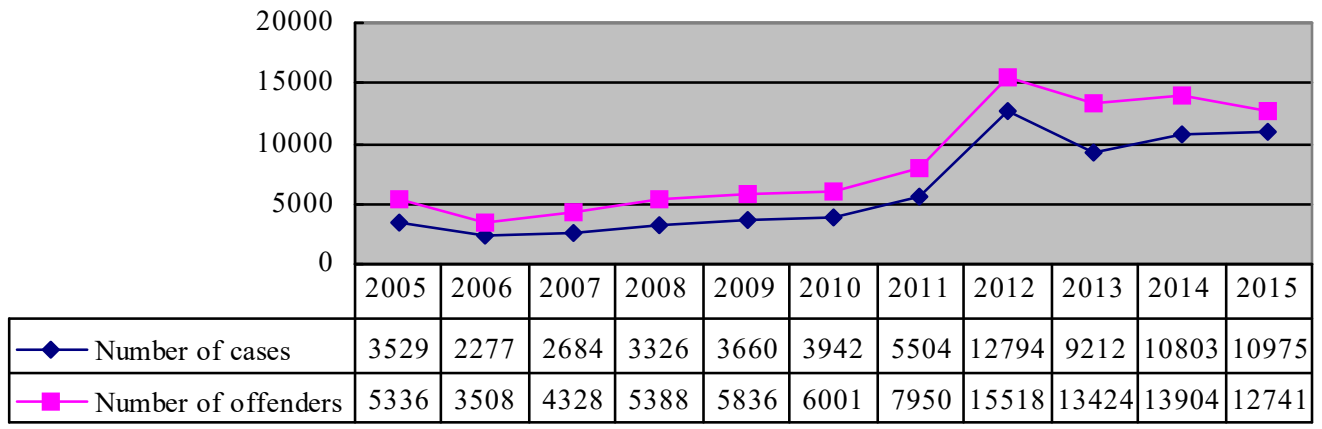

\subsection{Distribution characteristics of specific crimes}

As shown in Table 2, on the one hand, the number of cases of intellectual property crimes in a narrow sense increased from 505 cases in 2005 to 5103 cases in 2014 , with a significant upward trend; On the other hand, although the growth rate of intellectual property crime in the broad sense is not significant, there is still an overall increase.

Table 2: The distribution number of intellectual property crimes in the first instance of the court in 2005-2015

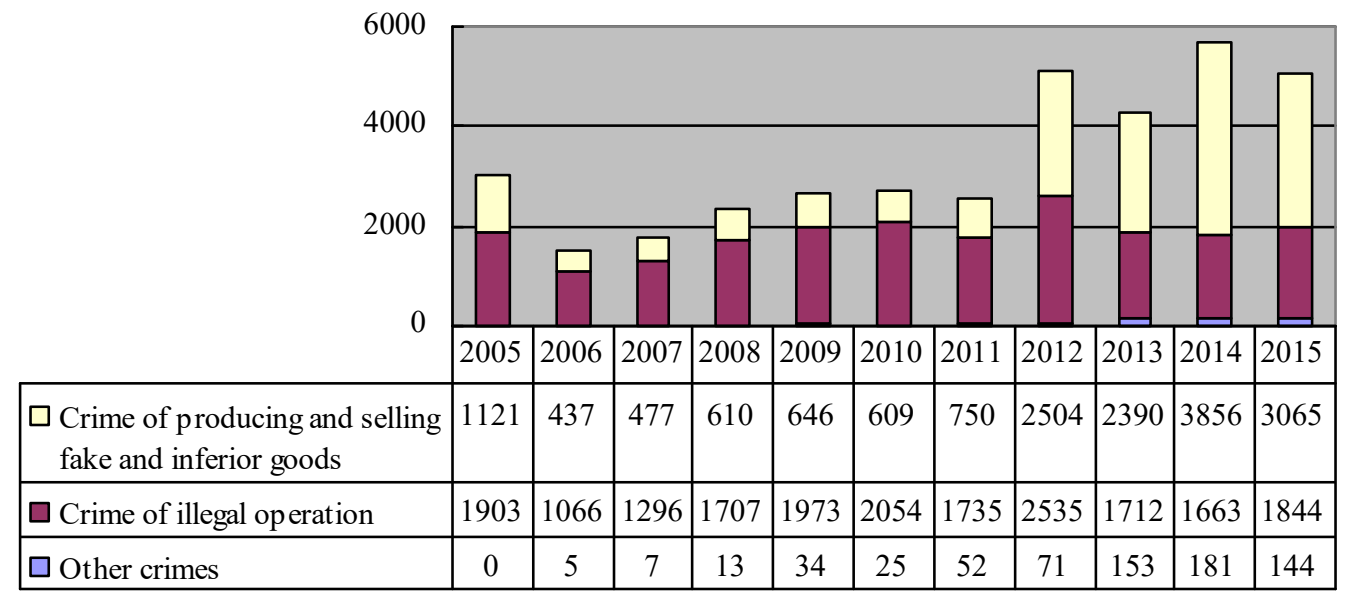

Table 3: Number of crimes against intellectual property rights in the national courts in 2015

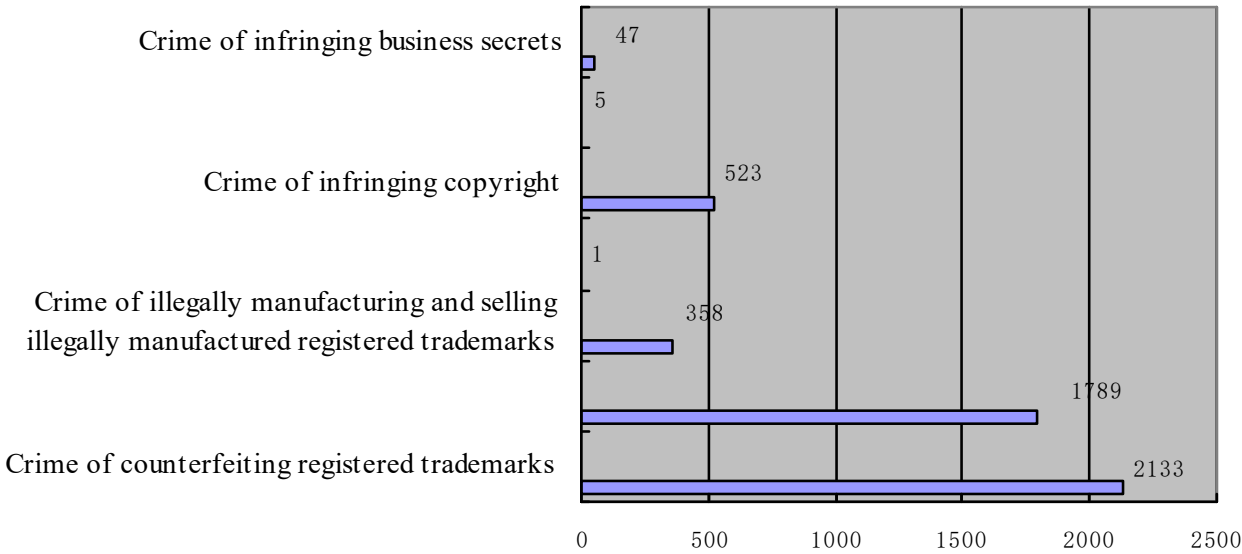


Table 4: The proportion of crimes against intellectual property rights in the national courts in 2015

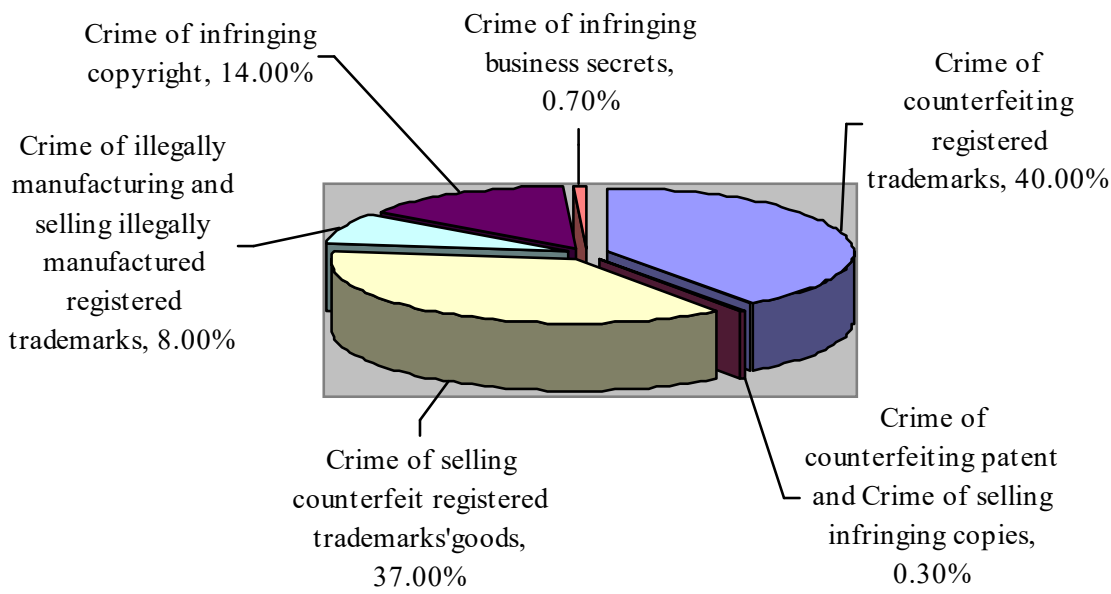

\subsection{The distribution characteristics of intellectual property crimes in a narrow sense}

As shown in Table 3, in 2015, the number of intellectual property infringement crimes in national courts in China reaches 4280 , followed by copyright infringement, while the number of other three crimes is significantly lower. Table 4 shows the proportion of each specific crime. The three crimes of infringement of the registered trademark right are the most common, and the crime of infringement of copyright also has a large proportion. Thus, in the criminal protection practice of seven special crimes, the related crime of trademark rights and copyright is the mainstream, which is related to the money worship under the tide of market economy, and has a great impact on the quality of the product and the reputation of the enterprise.

\subsection{Search data of Lawyee}

If you enter the crime of counterfeiting registered trademarks, counterfeit registered trademarks, and registered trademarks, you will find 138 in 2015, including 53 in Guangdong Province and 8 in Fujian Province (5 in Quanzhou, 2 in withdrawal, and 3 in Putian); There are 16 in 2016, including 4 in Guangdong Province, 3 in Fujian Province ( 2 in Longyan and 1 in Ningde) and 3 in Shandong Province. If you enter the crime of selling counterfeit registered trademarks' goods and counterfeit registered trademarks' goods, you will find 141 in 2015 and 7 in 2016; If you enter the crime of illegally manufacturing and selling illegally manufactured registered trademarks, manufacturing registered trademark marks, and registering trademark marks, you will find 9 in 2015 and 2 in 2016; If you enter the crime of copyright infringement, you will find 4 in 2016 and 24 in 2015.

Comparing the above four tables, it can be clearly seen that the "Lawyee" [5] as an important engine for legal search is not concerned with intellectual property crime and does not regard such crime as a common and multiple crime. There is a big contrast between this data and the reality, and the lack of typical cases also affects the study of such crimes.

\subsection{Search data of China judgement online}

If you search this website for the crime of counterfeiting registered trademarks, counterfeiting registered trademarks and registered trademarks, you will find in 2015, there are 662, including 49 in Fujian Province ( 2 in Longyan, 21 in Quanzhou, 6 in Fuzhou, 3 in Xiamen, 2 in Ningde, 9 in Putian, 1 in Nanping and 5 in Zhangzhou); In 2016, there are 252 in total, including 13 from Fujian Province (1 from Sanming, 3 from Putian and 9 from Quanzhou); If you enter the crime of selling counterfeit registered trademarks' goods and counterfeiting registered trademarks, you will find 727 in 2015, including 49 of Fujian Province ( 2 in Xiamen, 2 in Longyan, 9 in Quanzhou, 5 in Zhangzhou, 18 in Putian, 9 in Fuzhou, 2 in Nanping, 2 in Ningde); In 2016, there Are 429 items, of which 5 are in Fujian ( 3 in Putian, 1 in Nanping, and 1 in Sanming); If you enter the crime of illegally manufacturing and selling illegally manufactured registered trademarks, manufacturing registered trademarks and registered trademarks, you will find 102 in 2015, including 12 in Fujian Province (1 in Longyan, 2 in Fuzhou, 1 in Nanping, 1 in Putian, 6 pieces in Zhangzhou and 1 in Ningde); There are 43 in 2016, of which 1 in Fujian Province (Zhangzhou); If you enter crime of infringing copyright, you will find in 2015, there are 173 copyright offences, including 2 in Fujian Province ( 1 in Fuzhou and 1 in Xiamen), 46 in 2016, of which 0 in Fujian Province.

\section{Analysis of the characteristics of intellectual property crime}

\subsection{The possibility of the existence of large-scale}




\section{crime black numbers}

"Criminal black number refers to a criminal case in a country or region that has occurred in society for a certain period of time, but has not been known by the judicial authorities for many reasons or has not been included in official crime statistics."[6] The crime black number is essentially a "hidden crime." Comparing the four tables above, it can be clearly seen that as a benchmark website for judicial openness, the "China Judgement Online" is short of data on intellectual property crimes. [7] Even if the factors involved in trade secrets are removed, this part of the crime is on the verge of being dispensable. However, the common sense and perception of life tell us that in the real and online world, the number of intellectual property crimes is high, the tension of intellectual property crimes is obvious, the existence of black number of large-scale crimes is extremely possible, and there is a certain market and public opinion foundation. [8]

\subsection{The expansion of the scope of crime in the real world}

The crime of infringing intellectual property rights is flooded with many areas of economic life, and the crime of counterfeiting registered trademarks involves a wide range of crimes. [9] "Counterfeiters take advantage of the influence of international famous brands and their good quality and reputation to seek profits"[10]; The crime of illegally manufacturing and selling illegally made registered trademarks is characterized by strong regional characteristics. [11] The crime of selling counterfeit registered trademarks embodies the characteristics of greater profitability, is closely related to civil life, and has greater potential risk. [12] And the crime of copyright infringement appears from time to time. [13] Infringement of intellectual property rights has become a multiple crime, and the total amount is huge.

\subsection{The difficulty of eradicating the object of crime in the virtual world}

The combination of Internet intellectual property crime and network information technology is recognized worldwide as a new trend of development of intellectual property crime and the most serious threat in the new era. [14] Some counterfeit products are hard to distinguish from genuine and fake, and have great deception.[15] And well-known businesses endorse for them, and it is more difficult to investigate. For example, a large listed group is accused of "a lot of fake and inferior commodities, illegal goods are repeatedly removed but not enough, illegal behaviors are not well managed, and there is a tendency of selective avoidance". [16] For example, in August 2014, Hubei Province carried out an investigation on a number of websites unauthorized through the network to disseminate the group's magazine "Zhiyin Manke", investigated 3 websites, captured 5 suspects, and the amount involved in the case amounted to more than 1300 yuan. The remarkable feature of the
Internet world is the concealment. The characteristics of intellectual property crimes committed by criminals on the Internet have the characteristics of difficult discovery, difficult reporting, difficult jurisdiction, difficulty in obtaining evidence, difficulty in prosecution, difficult trial, difficult pursuit of stolen goods, and difficulty in obtaining compensation. It has greatly increased the difficulty of punishing and preventing such crimes, making the black number of such crimes inestimable.

\section{Conclusion: The implementation of the national intellectual property strategy}

"Globalization causes the internationalization of law, which is the universality of the law; The laws of every country are produced in their own soil and have their own characteristics. This is the particularity of the law." 3[17] The current intellectual property protection system has a passive form from the very beginning. [18] The judicial operation in the past twenty years is not ideal. As a developing country, different requirements for intellectual property based on strategy may have historical plausibility. But for a long time, the national conditions have been emphasized, too much attention has been paid to immediate results and lack of overall layout, which will easily lead to the rampant production and sale of fake goods, destroy public trust, good customs and enter the mutually harmful mode. In order to better reduce the number of intellectual property crimes and achieve sustainable development, we should conscientiously implement the national intellectual property strategy, eliminate the shortsightedness and local protectionism, and ensure the unified implementation of the law.

\section{References}

1. Sun Wanhuai. Proportion of Criminal Liability Basis for Crimes Against Intellectual Property Rights. Journal of East China University of Political Science and Law. No.1, 1999.

2. Huang Xiaoliang. Virtual Regression Reality: Challenges and Countermeasures of Criminal Law in the Age of Big Data. Journal of CUPL. No.4, 2015.

3. The Seismological Bureau, the Meteorological Bureau, and the Statistics Bureau are all accused by the Chinese people. The work of the Meteorological Bureau has improved significantly recently, and the Bureau of Statistics is still doing its part.

4. Data sources: 1998-2015 Intellectual Property White Paper, http://www.sipo.gov.cn/zwgs/zscqbps/; Judicial Protection of Intellectual Property Rights in Chinese courts, Separately, the People's Court Daily, April 10, 2010, April 19, 2011, April 23, 2012, etc.

5. Lawyee aims to provide the most authoritative, timely, comprehensive, normative and accurate legal advice. The relevant search results are lower than the author's estimate, and it seems to indicate the weak protection of intellectual property criminal law.

6. Xie Xiaodong. Criminal Black Number and Its Control. Science of Law. No.2, 2001. 
7. The China Judgement Online was officially implemented on January 1, 2014. Therefore, the lack of data is also normal. The author quotes the above data only to prove that compared with traditional criminal crimes, new crimes have not attracted enough attention.

8. On July 26, 2018, the social e-commerce business-Pin Duoduo successfully landed on the US stock market Nasdaq, and claimed to be the third-ranked e-commerce platform in China. However, in addition to the phenomenon of reverse consumption upgrade, the controversy that has attracted much attention has been questioned by its sales of cottage products. Seen in Pin Duoduo, the war of intellectual property! IPRdaily Chinese network (IPRdaily.cn) 2018-8-2.

9. Such as Shishi (2015) Shishi Criminal Word No. 597: Counterfeit "361" trademark logo; Hui'an (2015) Hui'an Criminal Word No. 449: Counterfeit "Anta" trademark; Luojiang (2015) Luojiang Criminal Word No. 35: Fake "NIKE" shoes; Quangang (2015) Quangang Criminal Word No. 155: Fake "Jordan" clothes and so on.

10. Registered trademarks related to counterfeiting are concentrated in "THE NORTH FACE", "Columbia", "LV", "GUCCI", "ROLEX", "OMEGA", "CD", "CHANEL", etc. Seen in Wan Haifu and Qin Tianning. Investigation of Shanghai Procuratorate's Cases of Infringement of Intellectual Property Rights. China Criminal Science. No. 6, 2010.

11. Such as Longyan Xinluo (2015) Longyan Xinluo Criminal Word No. 379: Making cigarette labels such as "Furong Wang"; Quanzhou (2015) Quanzhou Criminal Word No. 565: Making "Shuangta" and other monosodium glutamate logo; Yunxiao, Zhangzhou (2015) Yunxiao Criminal Word No. 142: Manufacturing cigarette logo; Zhao'an, Zhangzhou (2015) Zhao'an Criminal Word No. 101: Manufacturing of cigarette logo, etc.
12. Such as Yanping, Nanping (2015) Yanping Criminal Word No. 225: Sales of fake brand-name wines; Hanjiang, Putian (2015) Hanjiang Criminal Word No. 326: Sales of counterfeit "Adidas" shoes; Chengxiang, Putian (2015) Chengxiang Criminal Word No. 624: Sales of "New Balance" shoes; Xiangcheng, Putian (2015), Xiangcheng Criminal Word No.801: Fake "Jiu Muwang" bathroom; Gulou, Fuzhou (2015), Gulou Criminal Word No. 274: Sales of counterfeit "NIKE" shoes; Sale of fake wine; Hui'an (2015) Hui'an Criminal Word No. 620: Sales of fake "Jordan" clothes; Licheng, Putian (2015), Licheng Criminal Word No.287: Sales of "New Balance" shoes.

13. The "sword net 2014" special action clearly requires that all kinds of network infringement piracy should be severely punished, and the copyright operation of network carrier, including network TV bar and TV set-top box, should be emphasized.

14. Mao Qing. Internet Becomes the Hardest Hit Area for Intellectual Property Infringement. Nanjing Daily. April 24, 2013.

15. For example, in 2011, Fujian and Zhejiang cracked down on the "Taobao.com" online store that counterfeited and sold trademarks infringing on others. The total value involved was 88.42 million yuan.

16. Seen in "Alibaba and the General Administration of Industry and Commerce Continue to Expand Fighting", Tianya Forum, http://bbs.tianya.cn/post-333-616597-1.shtml.

17. Lu Qinzhong. "Research on the Internationalization of China's Financial Criminal Law", Chinese People's Public Security Research Press. 2004, 27.

18. The State party has an obligation to translate international treaties into domestic law, and the Geneva Conventions and the Uruguay Negotiations impose obligations on members' intellectual property systems and criminal protection systems. 